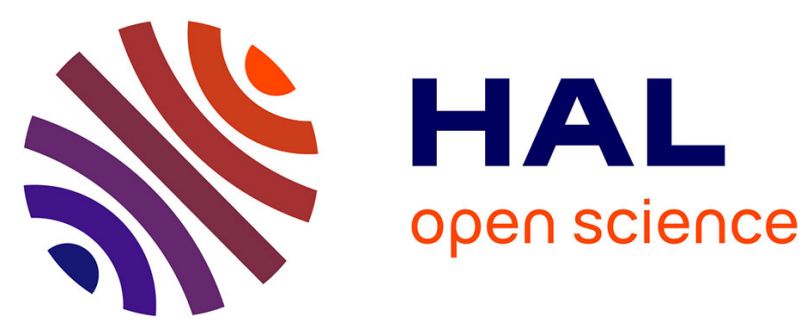

\title{
Influence of Different Parameters on Flashover Propagation on a Solar Panel
}

Virginie Inguimbert, Jean-Michel Siguier, Pierre Sarrailh, Jean-Charles Mateo-Velez, D. Payan, Gael Murat, Carsten Baur

\section{To cite this version:}

Virginie Inguimbert, Jean-Michel Siguier, Pierre Sarrailh, Jean-Charles Mateo-Velez, D. Payan, et al.. Influence of Different Parameters on Flashover Propagation on a Solar Panel. IEEE Transactions on Plasma Science, 2017, 45 (8), pp.1864-1870. 10.1109/TPS.2017.2686653 . hal-01705283

\section{HAL Id: hal-01705283 \\ https://hal.science/hal-01705283}

Submitted on 16 Feb 2018

HAL is a multi-disciplinary open access archive for the deposit and dissemination of scientific research documents, whether they are published or not. The documents may come from teaching and research institutions in France or abroad, or from public or private research centers.
L'archive ouverte pluridisciplinaire HAL, est destinée au dépôt et à la diffusion de documents scientifiques de niveau recherche, publiés ou non, émanant des établissements d'enseignement et de recherche français ou étrangers, des laboratoires publics ou privés. 


\title{
Influence of Different Parameters on Flashover Propagation on a Solar Panel
}

\author{
Virginie Inguimbert, Jean-Michel Siguier, Pierre Sarrailh, Jean-Charles Matéo-Vélez, \\ D. Payan, Gaël Murat, and Carsten Baur
}

\begin{abstract}
This paper first presents a short review of the recent experiments performed on large test fixtures, whose aim was to evaluate the flashover (FO) propagation during an electrostatic discharge. Then, the model of plasma bubble expansion is presented and compared with the results collected during the review. We will show that the model can represent qualitatively and quantitatively most of the results. The parameters of the model are mainly the ion velocity and the backscattered electron emission yield. The other experimental parameters influencing the FO propagation will be discussed.
\end{abstract}

Index Terms-Dielectric, discharge, flashover, simulation, spacecraft charging.

\section{INTRODUCTION}

A SATELLITE in geostationary orbit is submitted to different fluxes of particles that can lead to absolute and differential charging. In particular, during geomagnetic storms, higher fluxes of surface charging electrons (a few tens of kiloelectronvolts) can induce high negative potential on the satellite reference. Due to photoemission, dielectrics in sunlight, such as coverglasses on the surface of solar panels, are then less charged and an inverted potential gradient (IPG) is built between the cells and their coverglasses. This situation is at the origin of electrostatic discharges (ESDs), which can occur on the cell's edge, on interconnectors, or on any triple point made of a biased conductor, a charged dielectric, and vacuum.

When the ESD occurs, there is a first neutralization of the satellite capacitance (charged to absolute satellite potential) and a neutralization of the charged solar cell coverglasses (charged by the gradient, i.e., the differential potential). The first neutralization current is called blow-off (BO) and the second flashover (FO). They are both important to know because their amplitude and duration have to be represented during the on-ground tests with equivalent circuits. These circuits have to be sized correctly to be representative to what is going on in space on a charged floating satellite with its particular geometry. Sizing the charging circuit to represent the BO is simple and now well known, but the FO is a current, which is still subject to discussion and experimental

Manuscript received July 13, 2016; revised December 13, 2016; accepted March 14, 2017.

V. Inguimbert, J.-M. Siguier, P. Sarrailh, J.-C. Matéo-Vélez, and G. Murat are with ONERA, 31400 Toulouse, France (e-mail: virginie.inguimbert@onera.fr)

D. Payan is with CNES, Toulouse, France.

C. Baur is with the ESA, Noordwijk, The Netherlands.

Color versions of one or more of the figures in this paper are available online at http://ieeexplore.ieee.org.

Digital Object Identifier 10.1109/TPS.2017.2686653

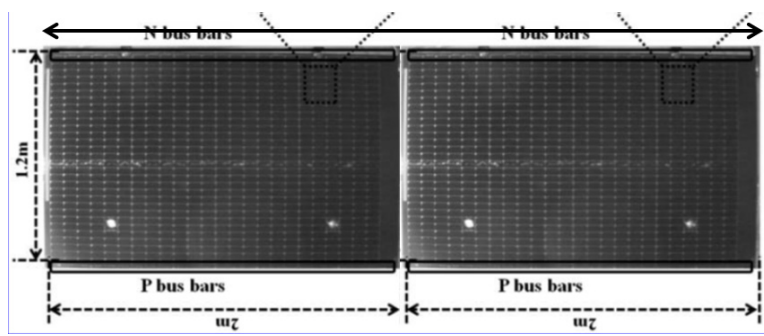

Fig. 1. Solar panel assembly used in [1] and [2].

evaluation. For many years, studies have been performed to experimentally estimate the characteristics of the FO such as maximum propagation surface and velocity to determine maximum duration and amplitude to be used in an FO equivalent circuit. Some of these studies are presented in the following paragraph reviewing, in particular, the experiments performed on large test fixtures.

\section{REVIEW OF RECENT EXPERIMENTS PERFORMED ON LARGE TEST FIXTURES}

Concerning the tests performed recently on solar panels, one can observe the tests performed in Japan and published by Mashidori et al. [1] and Okumura et al. [2] (see Fig. 1). During two test campaigns, they have worked on an assembly of two solar panels of $2 \mathrm{~m} \times 1.2 \mathrm{~m}$ each leading to a large test area of $4.8 \mathrm{~m}^{2}$.

Their objectives were to evaluate FO velocity and maximum expansion. The diagnostics were current probes on the strings and a camera with an image intensifier.

In these tests, the set of data is very large since all strings were instrumented, which will be very useful in the following to make comparisons. The maximum expansion, which was measured, was $3.75 \mathrm{~m}$ and the velocity determined by the camera was between 0.8 and $1.2 \times 10^{4} \mathrm{~m} / \mathrm{s}$.

The different tests performed in the frame of the U.S. roundrobin and published by Vayner et al. [3] and Young et al. [4] were also performed on a large assembly of solar cell coupons. In this case, the strings were also instrumented, but the geometry is fairly complex. Hence, as it can be seen in Fig. 2, some strings are in one direction since the others are perpendicular making a direct analysis more difficult than when strings are all parallel or concentric. However, the results are very interesting because surface potential was measured all over the surface allowing the evaluation of the coverglass charge, in particular, in the case of an IPG produced with electrons. Concerning FO velocity, the authors talked about the 


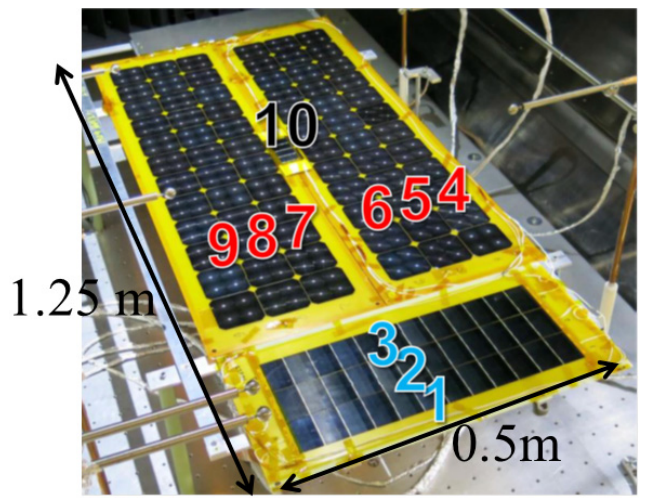

Fig. 2. Solar cell assembly used in [3] and [4].

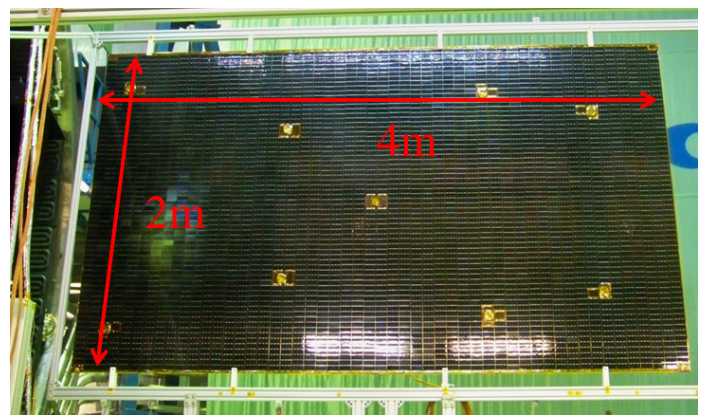

Fig. 3. Solar panel used in [5].

distribution of velocities and/or variable velocity from a few kilometers per second to a few tens of kilometers per second.

Finally, we will cite our results obtained during the EMAGS3 project, which were performed on an $8-\mathrm{m}^{2}$ panel [5] (see Fig. 3).

During different experimental configurations, the main objective was to evaluate the largest expansion of the FO and the parameters governing its propagation such as effect of the dielectric capacitance or position of the discharge.

As we were more oriented toward the determination of FO velocity, different tests were performed on concentric rings structures, mainly made of metalized Kapton.

We cite some published by Siguier et al. [6] (see Fig. 4), some by Young and Crofton [7] (see Fig. 5), and finally by Suzuki et al. [8] (see Fig. 6). For the same objectives with different shapes (see Figs. 7 and 8), we can also raise the results in the frame of the U.S. round-robin and those published by Hoffman et al. [9] and those made in France and published by Siguier et al. [6].

From all these tests, a lot of results were gathered and a lot of discussions have been developed on the different ways to interpret these results and particularly the FO velocity.

If we look at the similarities between these different results, the following are observed.

1) Near simultaneous onset of current in all segments.

2) Several maxima in the pulse currents.

3) The neutralization by FO is attenuating with distance.

4) The whole surface is not discharged each time.

5) When neutralization is partial, currents tend to end on all segments at the same time.

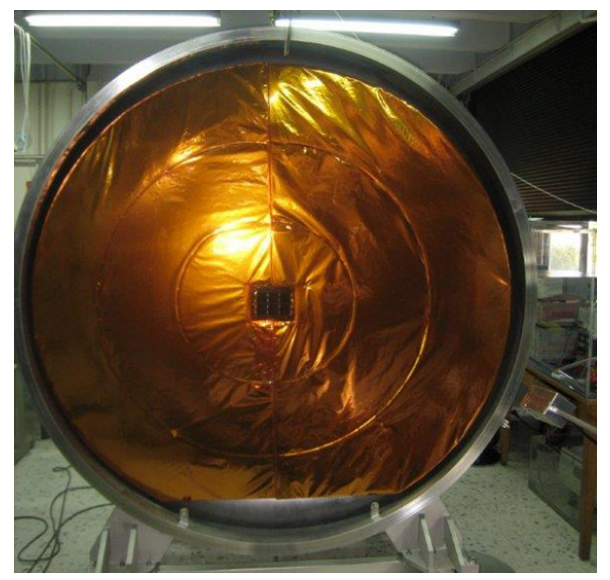

Fig. 4. Structure of $1.8 \mathrm{~m}$ of diameter made of three concentric rings in metallized Kapton used in [6].

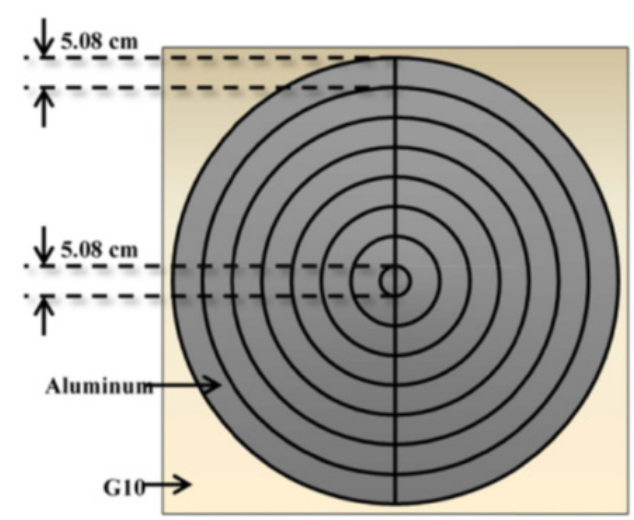

Fig. 5. Structure of $0.8 \mathrm{~m}$ of diameter made of eight concentric rings in metallized Kapton used in [7].

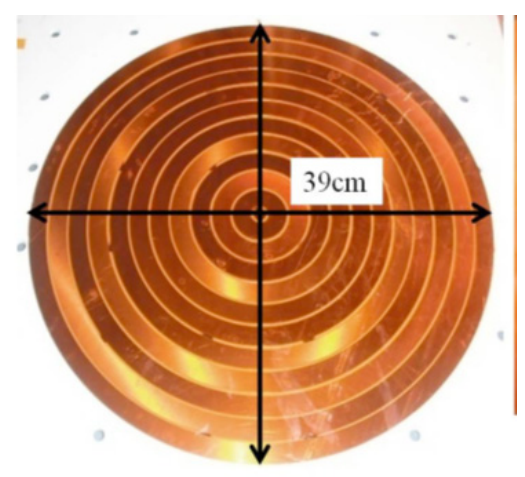

Fig. 6. Structure of $0.8 \mathrm{~m}$ of diameter made of 12 concentric rings in metallized Kapton used in [8].

6) Geometrical effects are observed, for instance a better neutralization if the sample is isotropic.

7) The potentials on the surface do not always go back to $0 \mathrm{~V}$ (mainly in electron IPG).

Now, if we look at the discrepancies, we can remark that they concern mainly the interpretation, which is made of the results. The interpretations are particularly different on velocities. The FO is interpreted to have either constant or variable velocity, a velocity distribution, or different 


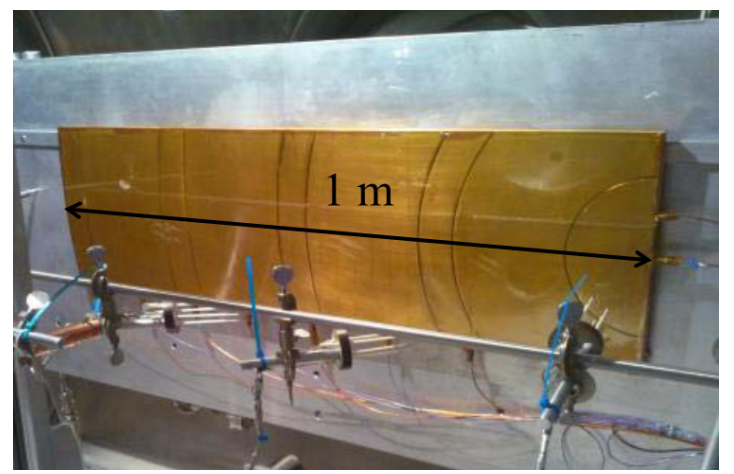

Fig. 7. Rectangle of $1 \mathrm{~m}$ long and $0.3 \mathrm{~m}$ wide used in [9].

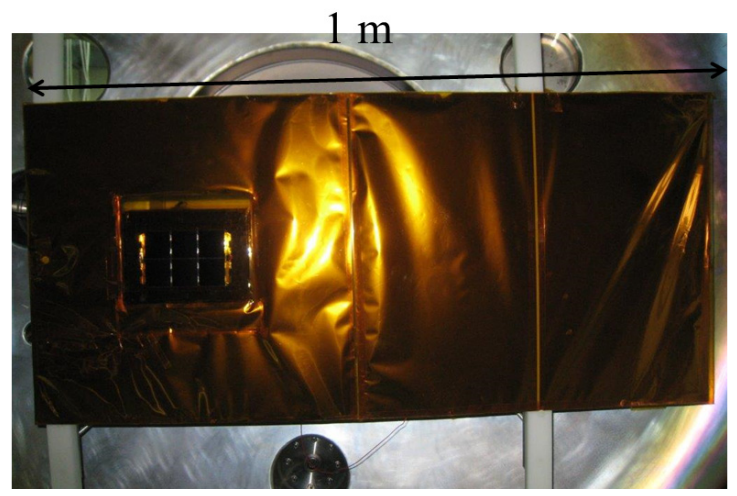

Fig. 8. Rectangle of $1 \mathrm{~m}$ long and $0.5 \mathrm{~m}$ wide made of three segments in metallized Kapton used in [6].

component velocities. This leads to values from a few to several hundreds of kilometers per second.

Despite a lot of discordances in the interpretation, the results are quite similar, and even if they are performed in a lot of different chambers on different test fixtures, a lot of observations are common. If we look at the results on large panels or if we extrapolate the results obtained on small text structures, we can agree that a discharge on a complete panel corresponds to an FO of a few amperes during a few hundreds of microseconds.

This result will be used to reproduce the FO through an equivalent circuit called the FO simulator. Before that, the next section is devoted to the comparison of the plasma model developed in [10] with the results obtained by the different teams.

\section{Application of Plasma Bubble Expansion Model to Several CASes}

\section{A. Rationale of the Plasma Bubble Expansion Model}

Different models have been developed to reproduce the FO expansion. For instance, the perimeter theory has been developed to reproduce the shape of the FO and explains its extinction [11]-[13]. Then more complex and more physical models have been developed based on Particle-in-Cell methods [14], [15], but they require long calculation times to get good statistics.

Sarrailh et al.'s model [10] developed in the frame of EMAGS3 project is a model based on the following assumptions.

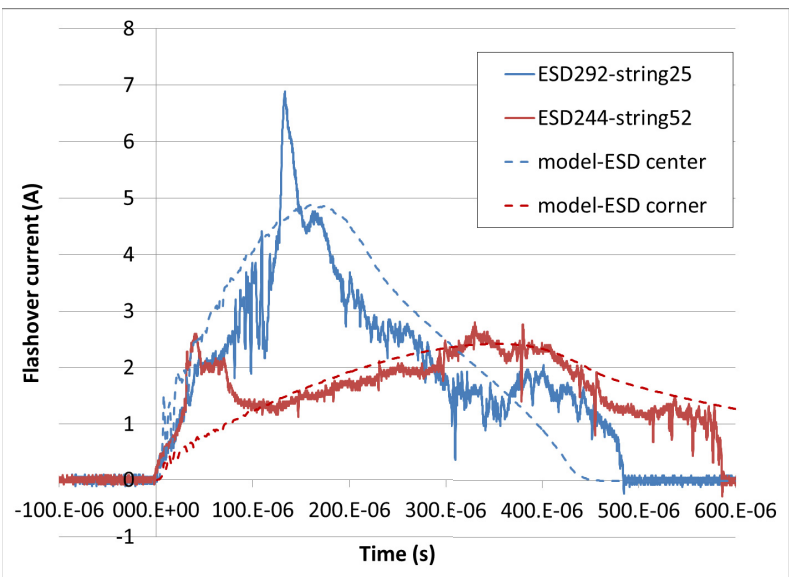

Fig. 9. Examples of two discharges occurring for the first one in the center of the panel and discharging the total charge of the surface and another discharge occurring in the corner of the panel and partially neutralizing the panel. Both are well reproduced with the model $\left(v_{i}=4500 \mathrm{~m} / \mathrm{s}, Y_{s}=0.37\right)$.

After the BO, which corresponds to an emission of electrons, which empties the satellite capacitance and brings back the panel potential to $0 \mathrm{~V}$, the plasma bubble starts to expand isotropically with a constant velocity.

The plasma bubble instantaneously neutralizes the dielectric potential.

Outside the plasma bubble, electrons extracted from the bubble are collected by the solar panel and this current is space charge limited and uniform. They create secondaries and only backscattered electrons are taken into account, leading to a current redistribution on the surface. The FO corresponds to the total electron current collected by the surface, i.e., electrons extracted from the bubble minus the current from the secondaries. The potential varies due to the net current collected and the conducted current is neglected. We need to highlight the point that the model does not apply if the BO duration is equal to the FO duration, i.e., in the case of a large value of satellite capacitance $C_{\mathrm{sat}}$, and when the effects of walls or the effects of geometry make the potential of the panel not neutralized during the expansion of the plasma.

\section{B. Validation of the Model}

This model was validated on results obtained in the frame of the EMAGS3 project, i.e., on a large solar panel. One can refer to [10] to see these results and an example is given here with two discharges obtained in the center or in the corner of the panel (Fig. 9), which are well reproduced with an ion velocity $v_{i}$ of $4500 \mathrm{~m} / \mathrm{s}$ and a backscattered electron yield $Y_{s}$ of 0.37 . Let us note that in the case of ESD244, the discharge stops before neutralizing the whole panel surface. In this case, an artificial interruption is introduced in the model, which stops the FO signal when a certain amount of charge is neutralized (corresponding to the one observed experimentally). If this artificial stop is not introduced, the FO expands until the whole surface is neutralized (as in the case of ESD292).

\section{Comparison With Concentric Ring Experiments}

The model was used to reproduce the results obtained during the tests with concentric rings shown in Fig. 4. 


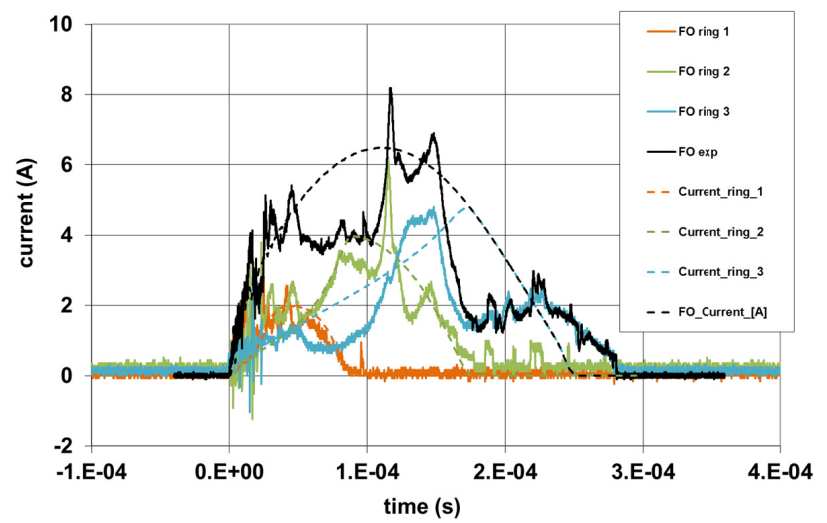

Fig. 10. Example of a discharge neutralizing completely the structure made of three concentric rings used in [6] and compared with the model using $v_{i}=3400 \mathrm{~m} / \mathrm{s}$ and $Y_{s}=0.37$.

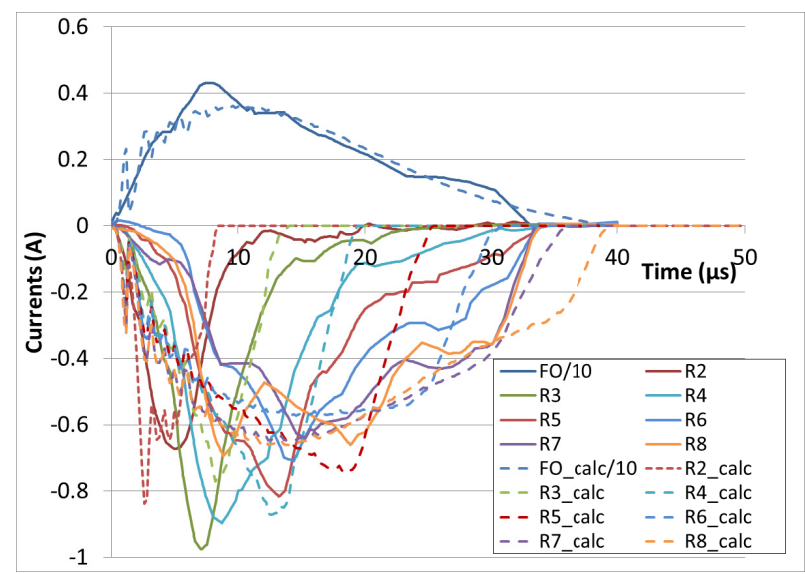

Fig. 11. Comparison of the model with an example of a discharge measured on the test fixture presented in Fig. 5 and published in [7].

An example of a discharge neutralizing completely the structure is compared with the model using a velocity of $3400 \mathrm{~m} / \mathrm{s}$ and presented in Fig. 10.

We observe in Fig. 10 that the model correctly represents the fact that current collection starts on all rings at the same time at the beginning of the ESD and ends sequentially. It does not represent the strong variations on the signals that are attributed to variability of the cathodic spots.

The model was then applied to a discharge obtained on the test fixture presented in Fig. 5 and published in [7]. It is an assembly of eight concentric rings made of aluminized Kapton. Each ring is instrumented. In Fig. 11, the measurements are represented by the continuous lines and the calculation by the dotted lines.

The plasma velocity was set to $9 \mathrm{~km} / \mathrm{s}$ and the backscattered electron yield was quasi-doubled (0.6 instead of 0.37 ) compared with the previous results in order to fit the very sharp front edge of the currents and the position of their maxima.

With these parameters, the simultaneous onset of all currents and the sequential end, at least of the first rings, are well represented.

Concerning the velocity and the ions of the electrode being aluminum, the velocity does not have to be increased

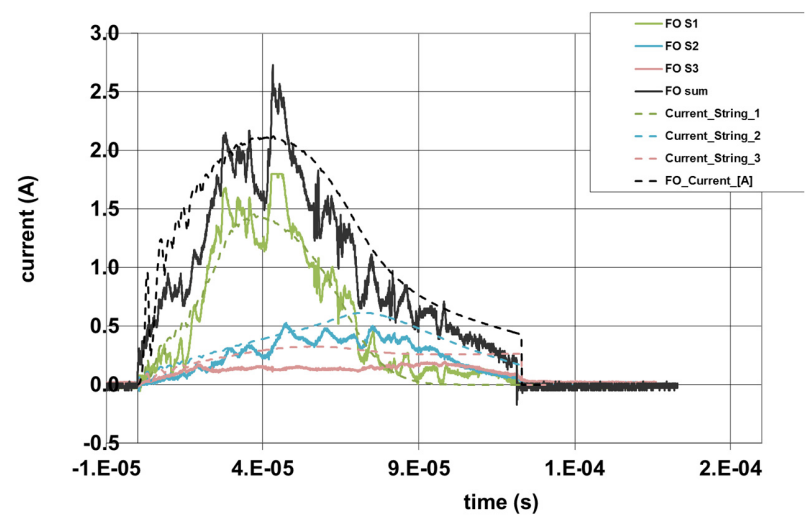

Fig. 12. Comparison of the model with a partial discharge on the three segments of the rectangle structure used in [6].

that much and another reason has to be found to explain such an increase in the velocity compared with the previous experiment.

Concerning the backscattered electrons, their evaluation is complicated since we do know their exact energy (something about $100 \mathrm{eV}$ ) and their incidence angle on Kapton. What we know, however, that this yield, about 0.2 at normal angle and $1 \mathrm{keV}$, is subject to increase with angle and on lightweight materials, when the incident energy decreases. A value of 0.6 is not that impossible and, maybe, the previous value of 0.37 was more underestimated. It means that this yield was also certainly higher in the previous calculation, but a nonnegligible part of these secondaries were not recollected by the panel.

\section{Comparison with a Rectangle Structure}

The model was compared with results obtained on a rectangle structure made of three rectangles of metalized Kapton.

The results are presented in Fig. 12.

The velocity of $3700 \mathrm{~m} / \mathrm{s}$ was conserved in this calculation (the same as in Fig. 10), but in order to represent the results, the potential in the model was not set to the experimental value of $600 \mathrm{~V}$ instead of $800 \mathrm{~V}$ and the calculation was stopped before complete neutralization of the rectangle, both in order to represent the partial neutralization. Hence, looking at how suddenly this discharge stops and calculating the amount of neutralized charge, it is clear that this discharge was only partial in terms of surface and even in terms of potential.

\section{E. Application to other Solar Panel Experiments}

The model was then applied on the experiments published by Okumura et al. [2] and obtained on the panel assembly shown in Fig. 1. As the signals measured on each string were not published, the comparison was performed only with the FO shape shown in Fig. 13 and with the neutralized charge on each string shown in Fig. 14. A very good agreement is observed with a velocity of $2500 \mathrm{~m} / \mathrm{s}$ and FO stopped when the neutralized amount of charge is equal to the experimental value given in Fig. 14.

To represent the charge neutralized on each string (Fig. 14), the initial surface potential is chosen to be completely uniform but with a slight decrease on the edges. 


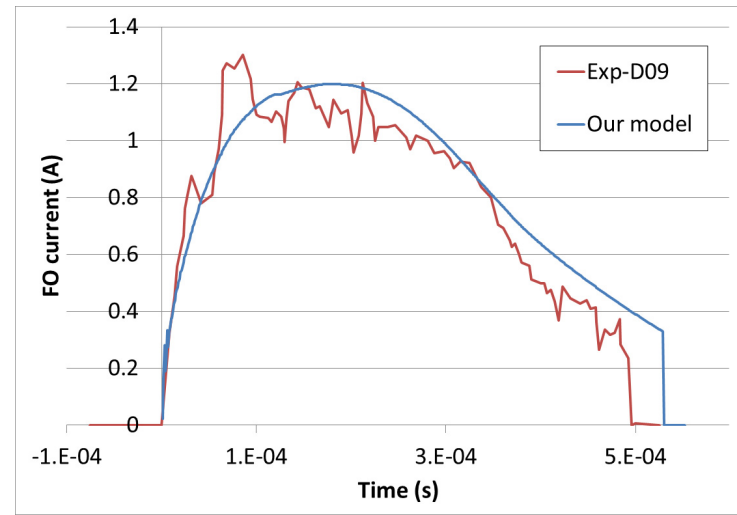

Fig. 13. Comparison of the model with one of the results (FO signal) published in [2] and obtained on a large solar panel.

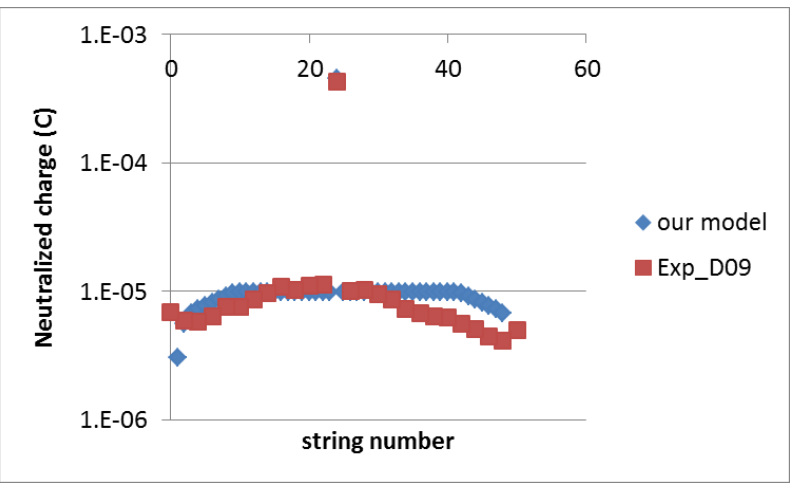

Fig. 14. Comparison of the model with the same result as in Fig. 13 but presenting the charge neutralized on each string.

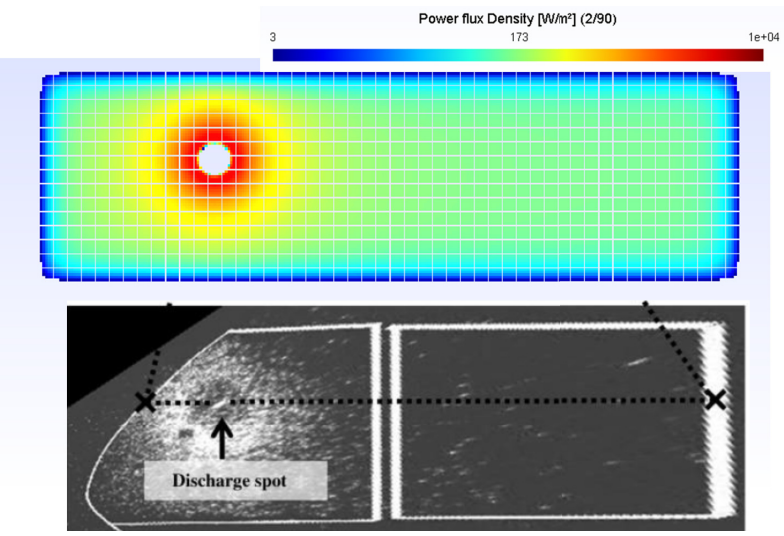

Fig. 15. Comparison of the model (power flux density) compared with the IR image taken and calculated $20 \mu$ s after ESD onset.

In this experiment, an IR camera was used to capture an image of the FO (see the bottom image in Fig. 15). A hypothesis is that the emitted light in this image can be related to absorbed power more than to collected current. The calculated absorbed power is thus calculated by the model and we can see on the top image of Fig. 15 that it qualitatively represents the observations made by the authors. Let us note that this calculation was performed on the same simulation as for the results presented in Figs. 13 and 14.

Another example of application of the model to a measurement published in [9] is given in Fig. 16. In Fig. 16(a) and (b),
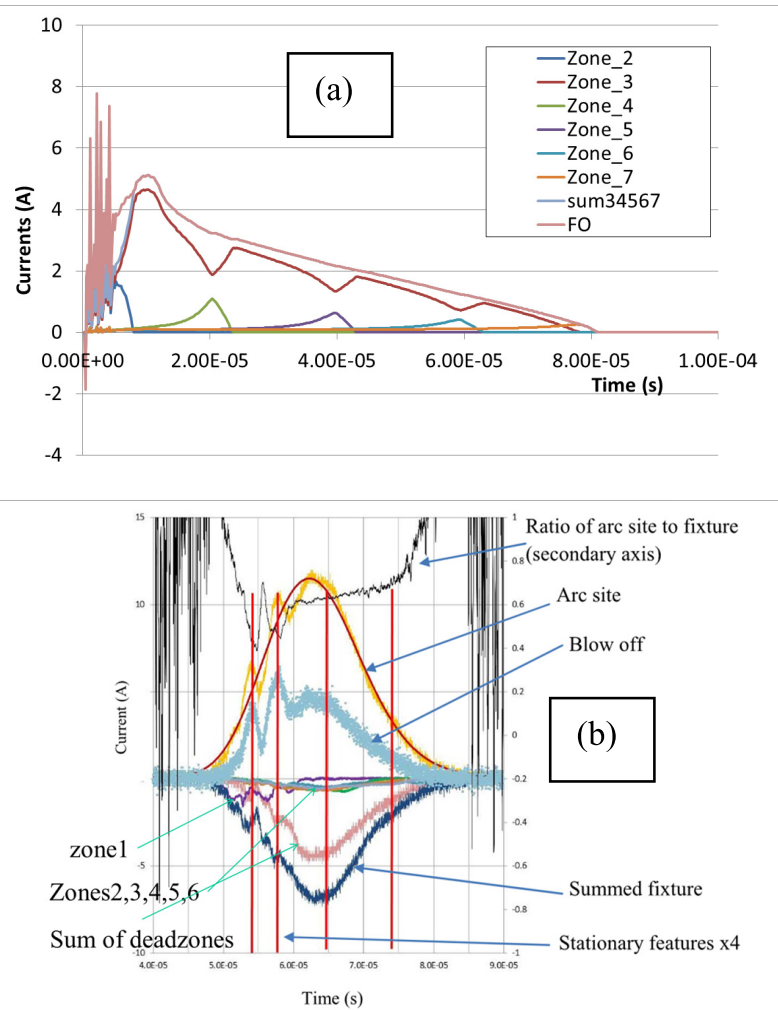

Fig. 16. (a) Comparison of the model with the results obtained during a discharge obtained on the text fixture presented in Fig. 7 and published in [9]. In the calculation, the ion velocity is $12 \mathrm{~km} / \mathrm{s}$. (b) Experimental data.
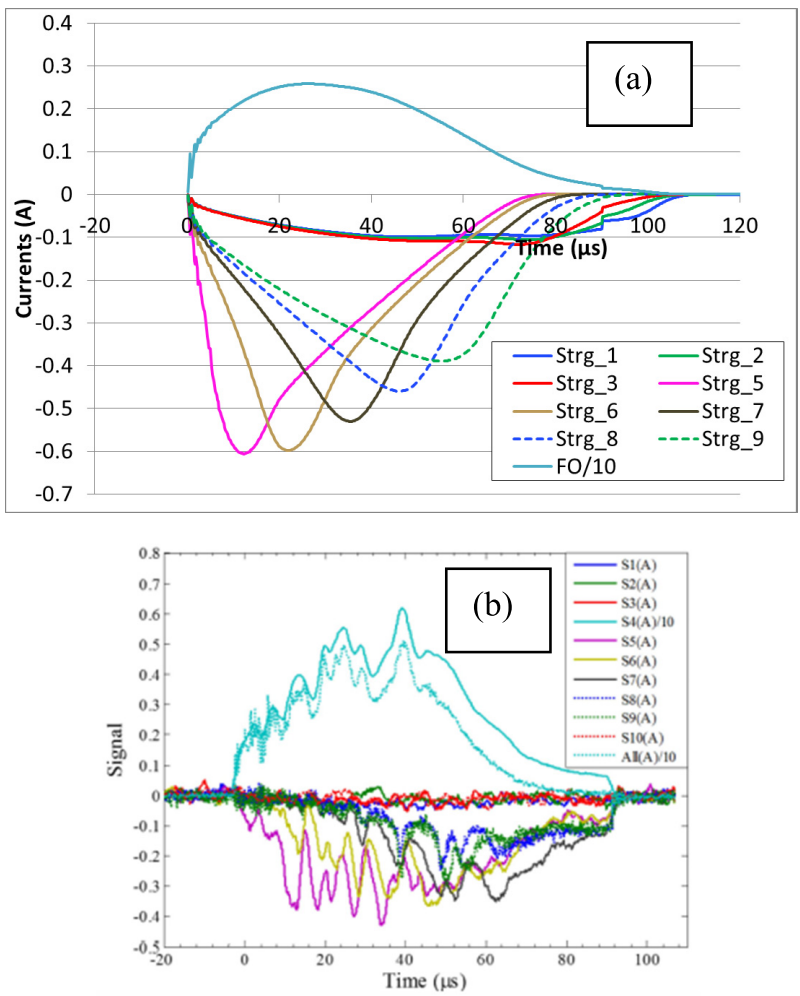

Fig. 17. (a) Comparison of the model with the results obtained during a discharge obtained on the text figure presented in Fig. 2 and published in [4]. (b) Experimental data.

the calculation by the model and the experimental data are given, respectively. In this case, the model does not represent what is measured and we show here its limitations since it 
cannot represent what happens when the $\mathrm{BO}$ and $\mathrm{FO}$ durations are equivalent, which is typically the case in this example.

Finally, the model was compared with the results published in [4]. We see in Fig. 17(a) and (b) [model and experiments] that agreement is qualitatively obtained even if the parameters were not optimized. Hence, due to the complexity of the text fixture, which does not make easy the interpretation and the simulation of the measurements, there are, however, quite well reproduced taking an ion velocity of $6 \mathrm{~km} / \mathrm{s}$.

Concerning this last experiment, it does not seem that the physical way the strings are arranged on the surface plays any role on the FO propagation or on the electrical arrangement. To confirm this assertion, one can refer to [17], where modifications of the surface and different electrical arrangements have been tested, which did not change in any way the plasma bubble expansion.

\section{CONCLUSION}

We have seen that the model of plasma bubble expansion can be applied to most of the data that have been collected. This model is based on the idea that there are different phenomena that participate in the neutralization process: the expansion of the plasma bubble, the extraction of the electrons from the plasma bubble that are collected by the charged surface and emitted by the impact of the primaries on the dielectric surface. The ion velocity is the sound velocity, but the electron velocity is very high and explains why the current collection starts everywhere at the same time. Then, we can assimilate the FO velocity more as a group velocity instead of as a single value.

The ion velocity taken to simulate the different results varied from 2.5 to $12 \mathrm{~km} / \mathrm{s}$. This parameter depends on ion mass, but this is not enough to explain such differences since the encountered materials are aluminum, silicon, germanium, or silver, which have mass variation only by a factor of four. Further parametric studies are needed to study the effect of pressure or electric fields. It will help to better understand the phenomena and better describe them in such a physical model.

However, in its current status, the plasma bubble expansion is fast and reliable to describe the experimental results. It can be very easily used to size FO equivalent circuits for arcing test setups knowing the arc inception voltage, which is an input parameter acting directly on the signal's maximum. This model has already been used to size the FO simulator used for ESD and arcing tests at ONERA [5], [16]

\section{REFERENCES}

[1] H. Mashidori, M. Iwasa, K. Nitta, and K. Toyoda, "ESD plasma propagation measurements on large-scale solar panels in simulated LEO environment," in Proc. 6th Int. Symp. Space Technol. Sci., Hamamatsu, Japan, 2008

[2] T. Okumura, M. Imaizumi, K. Nitta, M. Takahashi, T. Suzuki, and K. Toyoda, "Flashover discharge on solar arrays: Analysis of discharge current and image," J. Spacecraft Rockets, vol. 48, no. 2, pp. 326-335, Mar./Apr. 2011.

[3] B. V. Vayner et al., "First preliminary results from U.S. round-robin tests," IEEE Trans. Plasma Sci., vol. 41, no. 12, pp. 3310-3322, Dec. 2013.
[4] J. A. Young et al., "Preliminary measurements of ESD propagation on a round robin coupon," IEEE Trans. Plasma Sci., vol. 43, no. 11, pp. 3939-3947, Nov. 2015.

[5] V. Inguimbert et al., "Measurements of the flashover expansion on a real-solar panel-Preliminary results of EMAGS3 project," IEEE Trans. Plasma Sci., vol. 41, no. 12, pp. 3370-3379, Dec. 2013.

[6] J. M. Siguier et al., "Parametric study of a physical flashover simulator," IEEE Trans. Plasma Sci., vol. 40, no. 2, pp. 311-320, Feb. 2012.

[7] J. A. Young and M. W. Crofton, "ESD propagation dynamics on a radially symmetric coupon," IEEE Trans. Plasma Sci., vol. 43, no. 10, pp. 3749-3759, Oct. 2015.

[8] T. Suzuki, T. Endo, H. Masui, K. Toyoda, and M. Cho, "Flashover current measurement using circle electrodes," in Proc. 12th Spaceraft Charging Technol. Conf., Kitakyushu, Japan, May 2012.

[9] R. Hofmann et al., "AFRL round-robin test results on plasma propagation velocity," IEEE Trans. Plasma Sci., vol. 43, no. 9, pp. 3006-3013, Sep. 2015.

[10] P. Sarrailh et al., "Plasma bubble expansion model of the flash-over current collection on a solar array-comparison to EMAGS3 results," IEEE Trans. Plasma Sci., vol. 41, no. 12, pp. 3429-3437, Dec. 2013.

[11] E. Amorim, D. Payan, R. Reulet, and D. Sarrail, "Electrostatic discharges on a $1 \mathrm{~m}^{2}$ solar array coupon-Influence of the energy stored on coverglass on flashover current," in Proc. 9th Spacecraft Charging Technol. Conf., Tsukuba, Japan, Apr. 2005.

[12] R. Briet, "Scaling laws for pulse waveforms from surface discharges," in Proc. 9th SCTC, Tsukuba, Japan, Apr. 2005.

[13] D. C. Ferguson and B. V. Vayner, "Flashover current pulse formation and the perimeter theory," IEEE Trans. Plasma Sci., vol. 41, no. 12 , pp. 3393-3401, Dec. 2013.

[14] J.-F. Roussel et al., "SPIS multiscale and Multiphysics capabilities: Development and application to GEO charging and flashover modelling,' IEEE Trans. Plasma Sci., vol. 40, no. 2, pp. 183-191, Feb. 2012.

[15] J. A. Young and M. W. Crofton, "The effects of material at arc site on ESD propagation," in Proc. 14th SCTC, Noordwijk, The Netherlands, Apr. 2016, pp. 1-7.

[16] A. Gerhard et al., "Analysis of solar array performance degradation during simulated flashover discharge experiments on a full panel and using a simulator circuit," IEEE Trans. Plasma Sci., vol. 43, no. 11, pp. 3933-3938, Nov. 2015.

[17] J.-M. Siguier, V. Inguimbert, P. Sarrailh, G. Murat, D. Payan, and N. Balcon, "Effect of surface discontinuities and electrical network architecture on the flashover," IEEE Trans. Plasma Sci., vol. 41, no. 12, pp. 3387-3392, Dec. 2013.

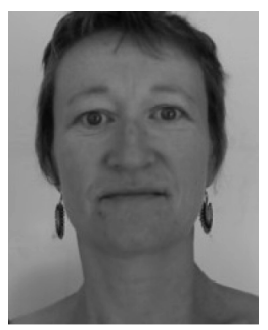

Virginie Inguimbert received the Ph.D. degree from the University of Toulouse, Toulouse, France, in 1995.

She has been with the Department of Space Environment, ONERA-The French Aerospace Lab., Toulouse, since 1996. She has been involved in the erosion of polymers by atomic oxygen, characterization of thermo-optical properties of materials, and the erosion and contamination of materials submitted to electric propulsion. She has also been involved in electrostatic discharge experimental activities, since 2002, and was named the Head of the Coupling Satellite-Environment group in 2009.

Dr. Inguimbert has served as a Referee for the IEEE TRANSACTIONS ON Plasma SCIENCE.

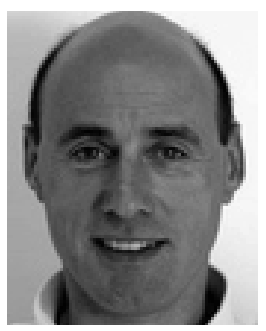

Jean-Michel Siguier received the Dipl.-Ing. degree from CNAM-Toulouse, Toulouse, France, in 1989.

$\mathrm{He}$ has been with the Space Environment Department, ONERA-The French Aerospace Lab., Toulouse, since 1979. He was developing a Secondary Electronic Emission facility (DEESSE) and a deep charging facility (SIRENE), from 1980 to 1995. From 1996 to 2007, he was involved in material characterization for stratospheric ballooning in collaboration with CNES-The French Space Agency. Since 2008, he has been involved in spacecraft charging, electrostatic discharge, and plasma-spacecraft interactions.

Mr. Siguier has served as a Referee for the IEEE TRANSACTIONS ON Plasma SCIENCE. 


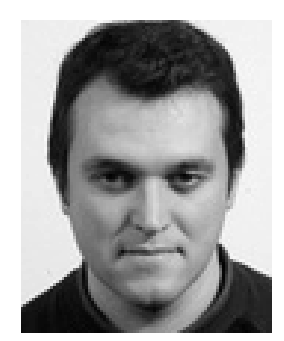

Pierre Sarrailh received the Ph.D. degree in plasma physics from University Paul Sabatier, Toulouse, France, in 2008.

In 2009, he joined the Department of Space Environment, ONERA-The French Aerospace Lab., Toulouse. He is currently a Research Scientist with the Coupling Satellite-Environment group. His current research interests include spacecraft plasma interactions modeling and the development of the numerical core of the Spacecraft Plasma Interaction Software (dev.spis.org).

Dr. Sarrailh has served as a Referee for the IEEE TRANSACTIONS on Plasma Science. He is a member of the Spacecraft Plasma Interaction Network in Europe.

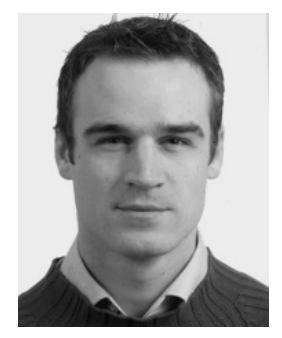

Jean-Charles Matéo-Vélez received the master's degree in engineering in fluid mechanics from the École Nationale Supérieure d'Electronique, d'Electrotechnique, d'Informatique, d'Hydraulique, et des Télécommunications, Toulouse, France, the master's degree in research in fluid dynamics from Toulouse University, Toulouse, in 2003, and the $\mathrm{Ph} . \mathrm{D}$. degree in fluid dynamics from SUPAERO, Toulouse, in 2006.

Since 2007, he has been a Research Scientist with the Space Environment Department, ONERA-The French Aerospace Lab., Toulouse. His current research interests include spacecraft charging, ground tests of ESDs, and numerical modelling of spacecraft-plasma interaction.

Dr. Mateo-Velez is a member of the Spacecraft Plasma Interaction Network in Europe. He has served as a referee for the IEEE TRANSACTIONS ON Plasma Science.

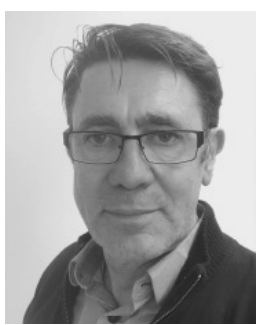

D. Payan is currently a Senior Expert in spacecraft charging and electrostatic risk. He has been with CNES-The French Space Agency Lab., Toulouse, France, for over 27 years in this field. $\mathrm{He}$ is the Project Manager of a CNES plasma monitor named AMBER (Active Measurement Box of Electrostatic Risk) measuring charging plasma and currently onboard the JASON-3 spacecraft.

$\mathrm{He}$ is also a member of the Spacecraft Plasma Interaction Network in Europe.

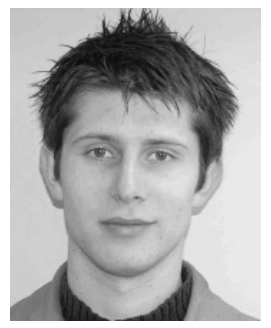

Gaël Murat received the technical degree in physical measurements and the license in instrumentation and test in complex environments from the University of Toulouse, Toulouse, France, in 2005 and 2006, repectively.

$\mathrm{He}$ has been with the Department of Space Environment, ONERA-The French Aerospace Lab. Toulouse, since 2009. He is responsible for the JONAS facility where all flashover tests are performed.

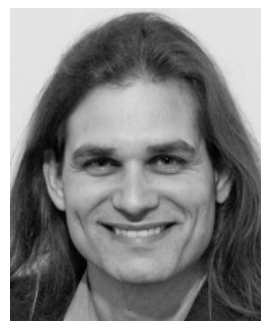

Carsten Baur received the Diploma in physics from the University of Freiburg, Freiburg, Germany, in 2002, and the Ph.D. degree in physics from the University of Konstanz, Konstanz, Germany, in 2007.

From 2000 to 2006, he was with the Fraunhofer Institute for Solar Energy Systems, Freiburg, where he did both his diploma and Ph.D. thesis in the field of the characterization of III-V solar cells for space applications. Since 2006, he has been with the European Space Agency, Noordwijk, The Netherlands, where he is mainly responsible for the definition and supervision of R\&D activities, most of which are related to the development of solar cells for space applications, but he also follows activities that are related to the investigation of space phenomena which can affect the performance of solar cells and the solar array such as electrostatic discharge effects. He has authored or co-authored over 50 papers published in international journals and international conferences. 